Pesq. Vet. Bras. 35(5):486-490, maio 2015

DOI: $10.1590 / \mathrm{S} 0100-736 \mathrm{X} 2015000500017$

\title{
Ocorrência do SNP c.767G >T no gene DNM1 responsável pelo colapso induzido pelo exercício em cães da raça Labrador Retriever no Estado de São Paulo ${ }^{1}$
}

\author{
Roberta M. Basso ${ }^{2}$, José P. Oliveira-Filho², Mariana I.P. Palumbo², Luiza S. Zakia², \\ João P. Araújo Jr³ e Alexandre S. Borges ${ }^{2 *}$
}

\begin{abstract}
Basso R.M., Oliveira-Filho J.P., Palumbo M.I.P., Zakia L.S., Araújo Jr J.P. \& Borges A.S. 2015. [Occurrence of DNM1 SNP c.767G $>$ T responsible for exercise-induced collapse in Labrador Retriever in the Sao Paulo state.] Ocorrência do SNP c.767G>T no gene DNM1 responsável pelo colapso induzido pelo exercício em cães da raça Labrador Retriever no Estado de São Paulo. Pesquisa Veterinária Brasileira 35(5):486-490. Departamento de Clínica Veterinária, Faculdade de Medicina Veterinária e Zootecnia, Universidade Estadual Paulista "Júlio de Mesquita Filho", Campus de Botucatu, Distrito de Rubião Junior s/n, Botucatu, SP 18618-970, Brazil. E-mail: asborges@fmvz.unesp.br

The exercise-induced collapse (EIC) is considered an autosomal recessive syndrome that mainly affects Labrador Retriever dogs. The disease is characterized by muscle weakness and collapse after intense exercise. Recovery usually occurs after exercise but some animals may die. The clinical signs occurs due to the single-nucleotide polymorphism (SNP) c.767G>T in Dynamin 1 (DNM1) gene. The aim of this study was to evaluate the occurrence of this SNP in 321 Labrador Retriever dogs from São Paulo state. Specific primers for amplification of the entire exon 6 of the DNM1 gene were used in a PCR performed with DNA from blood or buccal swab samples, direct sequencing was performed for the final evaluation. Among 321 animals studied, 3.4\% (11/321) of animals were homozygous for the DNM1 SNP (c.767G>T) and 24.6\% (79/321) were heterozygous. Only one of the 11 homozygous animals in this study had previous clinical signs compatible with this disease. This is the first study that evaluated the occurrence of DNM1 SNP (c.767G $>$ T) gene in Brazil and considering that almost $25 \%$ of the studied animals were heterozygous, the routinely evaluation of this SNP may be important before this breed mating The EIC should be include in the differential diagnosis of neuromuscular diseases in Labrador Retriever dogs.
\end{abstract}

INDEX TERMS: Dog, Labrador Retriever, DNM1, exercise, PCR, sequencing.

RESUMO.- 0 colapso induzido pelo exercício (EIC) é considerado uma síndrome autossômica recessiva que afeta principalmente cães da raça Labrador Retriever. A doença é caracterizada por fraqueza muscular e colapso após exercício intenso. Usualmente, ocorre recuperação clínica após o episódio, mas alguns animais podem vir a óbito. Os sinais

\footnotetext{
${ }^{1}$ Recebido em 10 de outubro de 2014.

Aceito para publicação em 28 de abril de 2015.

${ }^{2}$ Departamento de Clínica Veterinária, Faculdade de Medicina Veterinária e Zootecnia (FMVZ), Universidade Estadual Paulista "Júlio de Mesquita Filho" (Unesp), Distrito de Rubião Junior s/n, Botucatu, SP 18618-970, Brasil. *Autor para correspondência: asborges@fmvz.unesp.br

${ }^{3}$ Departamento de Microbiologia e Imunologia, Instituto de Biociências de Botucatu (IBB), Unesp, Distrito de Rubião Junior s/n, N, Botucatu, SP 18618-970.
}

clínicos são decorrentes do polimorfismo de base única (SNP) c.767G>T no gene Dynamin 1 (DNM1). 0 objetivo deste trabalho foi determinar a ocorrência deste SNP em 321 cães da raça Labrador Retriever do Estado de São Paulo. Primers específicos para a amplificação de todo o exon 6 do gene DNM1 foram usados nas PCRs utilizando DNA a partir de amostras de sangue ou swab bucal, a avaliação final foi realizada com sequenciamento direto dos produtos da PCR. Dentre os 321 animais estudados, 3,4 \% (11/321) eram homozigotos para o SNP c.767G>T no gene DNM1 e $24,6 \%(79 / 321)$ eram heterozigotos. Somente um dos 11 animais homozigotos apresentavam sinais clínicos compatíveis com a EIC. Este é o primeiro estudo sobre a ocorrência deste SNP no Brasil e considerando que quase $25 \%$ dos animais estudados eram heterozigotos, a genotipagem 
dos animais para este SNP pode ser importante antes dos acasalamentos para cães desta raça. A EIC deve ser considerada nos diagnósticos diferenciais de enfermidades neuromusculares em cães da raça Labrador Retriever.

TERMOS DE INDEXAÇÃO: Cães, Labrador Retriever, DNM1, exercício, PCR, sequenciamento.

\section{INTRODUÇÃo}

A intolerância ao exercício pode ser ocasionada por anormalidades cardíacas, respiratórias, osteomusculares ou neurológicas. 0 diagnóstico definitivo é fundamental para instituição do tratamento adequado. 0 colapso induzido pelo exercício (EIC) é uma síndrome diagnosticada com maior frequência em cães da raça Labrador Retriever (Taylor et al. 2008, Minor et al. 2011). Atualmente, é considerada a causa mais comum para a intolerância ao exercício em cães jovens desta raça (Taylor et al. 2008, Cosford \& Taylor 2010, Minor et al. 2011).

A análise do pedigree de Labradores Retrievers, registrados no Canadian Kennel Club e no American Kennel Club, que apresentavam EIC sugeriu que esta síndrome possuía um modelo consistente de herdabilidade autossômico recessivo (Taylor et al. 2008). Posteriormente, foi confirmado que a EIC é causada por um polimorfismo de base única (SNP) localizado no exon 6 do gene DNM1 (Patterson et al. 2008), codificador da proteína dinamina-1. Este SNP (c.767G>T) quando em homozigose (E/E) causa a troca de uma arginina por uma leucina, o que leva à uma anormalidade da transmissão sináptica pela diminuição da correta tradução da proteína dinamina-1 (Ferguson et al. 2007, Patterson et al. 2008). A dinamina-1 é responsável pela endocitose das vesículas sinápticas nos terminais nervosos durante um estímulo persistente e de alta frequência (Ferguson et al. 2007). Os neurônios podem suportar altas taxas de transmissão sináptica sem esgotar seu suprimento de vesículas sinápticas, isto devido à reciclagem que ocorre na fenda sináptica através da endocitose das vesículas que foram recém liberadas. Sendo assim, essas vesículas podem ser reutilizadas centenas ou milhares de vezes (Saheki \& De Camilli 2012).

Casos de EIC são descritos com maior frequência em Labradores Retrievers na Alemanha (Minor et al. 2011), Canadá, Estados Unidos (Taylor et al. 2008, Minor et al. 2011) e Japão (Takanosu et al. 2012) e no continente europeu. Contudo, o SNP responsável pela EIC já foi identificado em homozigose em cães das raças Chesapeake Bay Retriever, Curly-Coated Retriever (Patterson et al. 2008), Boykin Spaniel e Welsh Corgi Pembroke (Minor et al. 2011). Minor et al. (2011) genotiparam 1.170 cães de 15 raças não Retrievers e não encontraram nenhum genótipo $\mathrm{E} / \mathrm{E}$ ou E/N (heterozigoto) nestes animais.

Segundo Patterson et al. (2008), a maioria dos Labradores Retrievers E/E para o SNP (c.767G>T) é clinicamente normal em repouso, entretanto, apresentam o colapso ao serem submetidos a exercícios físicos intensos (Taylor et al. 2009, Minor et al. 2011). Labradores Retrievers com EIC após cinco a 20 minutos de exercício intenso apresentam dificuldade de movimentação dos membros posteriores e paraparesia flá- cida não dolorosa, progredindo para o colapso (Taylor et al. 2009). Os primeiros sinais apresentados pelos cães afetados incluem dificuldade de locomoção com andar cambaleante (Taylor et al. 2009). Normalmente, o animal permanece com nível de consciência normal (Furrow et al. 2013).

Possivelmente o aumento de temperatura corporal e a alcalose respiratória após exercício em cães de competição da raça Labrador Retriever estejam relacionadas com baixa performance ou com a EIC nestes animais (Steiss et al. 2004). Temperatura ambiental alta aumenta a probabilidade da ocorrência de colapsos, contudo, isto não é uma condição obrigatória, uma vez que foram relatados episódios de colapsos em temperaturas abaixo de $0{ }^{\circ} \mathrm{C}$ (Taylor et al. 2008). Portanto, deve-se evitar exercícios intensos e atividades que causem estresse aos animais portadores da EIC, sobretudo em dias com altas temperaturas (Taylor et al. 2008). Outra hipótese é de que temperaturas corporais altas, atingidas durante exercício intenso, contribuam para uma disfunção na proteína mutante, gerando assim, falhas na transmissão sináptica desencadeando os sinais da enfermidade (Matwichuk et al. 1999, Taylor et al. 2009). Sete dos 225 cães estudados por Taylor et al. (2008) morreram durante os episódios de colapso após exercício intenso. Porém, com a restrição dos exercícios físicos intensos houve diminuição drástica dos episódios de colapso ou total desaparecimento destes episódios na maioria dos animais.

Outras enfermidades, incluindo doenças metabólicas, cerebrais e cardíacas, podem ser responsáveis pelos colapsos observados em cães N/N (wild type) ou E/N para o SNP responsável pela EIC (Patterson et al. 2008, Furrow et al. 2013). Contudo, por não existir um exame realizado na rotina dos ambulatórios veterinários que confirme a síndrome, o diagnóstico se dá pela exclusão de outras doenças que estão relacionadas ao colapso e à intolerância ao exercício e pela observação dos sinais clínicos (Taylor et al. 2008). Entretanto, a genotipagem dos animais possibilita um diagnóstico específico e evita que criadores permitam que a doença seja transmitida para a prole (Minor et al. 2011). Considerando que a enfermidade tem grande importância clínica para animais da raça Labrador Retriever, raça comumente criada no Brasil, e embora recentemente tenha sido descrito um caso de EIC no Brasil (Basso et al. 2014), não existem estudos de ocorrência deste SNP em animais no país, sendo assim, o objetivo desta pesquisa foi avaliar a ocorrência do SNP (c.767G>T) no gene DNM1 responsável pela enfermidade em uma amostra de 321 cães desta raça provenientes do Estado de São Paulo.

\section{MATERIAL E MÉTODOS}

Neste estudo retrospectivo foram utilizadas amostras biológicas colhidas de Labradores Retriever durante o atendimento clínico no Hospital Veterinário (HV) da FMVZ, Unesp de Botucatu. Amostras de sangue $(n=312)$ ou swab bucal $(n=9)$ foram colhidas de 321 cães da raça Labrador Retriever, sendo 131 machos e 190 fêmeas, com diferentes colorações de pelagem e idades variando de 1 mês a 12 anos. Em seguida o DNA genômico foi extraído destas amostras com o Illustra Blood GenomicPrep Mini Spin Kit (GE ${ }^{\odot}$ Healthcare, Buckinghamshire, England), seguindo as recomendações do fabricante. A concentração do DNA obtido das amostras foi mensurada por espectrofotometria (Nanodrop ${ }^{\circledR}$ 2000, Ther- 
mo Scientific ${ }^{\mathrm{TM}}$, DE, USA) e o DNA foi armazenado no Banco de DNA do Laboratório de Biologia Molecular da Clínica Veterinária a $-20^{\circ} \mathrm{C}$ até a realização da PCR.

Primers específicos, descritos previamente por Patterson et al. (2008), que amplificam um fragmento de 337 pares de bases, contendo o SNP c.767G>T, DNM-1 Forward (5'-GTAGGCTCTCCGACCCACTC-3') e DNM-1 Reverse (5'-TGAGGACACTAACCCCTGTTG-3'), foram sintetizados e utilizados nas reações de PCR. A PCR foi padronizada com volume final de $20 \mu \mathrm{L}$, sendo $2 \mu \mathrm{L}$ de DNA, 400 nM de cada primer, $10 \mu \mathrm{L}$ de GoTaq ${ }^{\circledR}$ Green Master Mix (Promega $^{\mathrm{TM}}$, WI, USA) e 6,4 $\mu \mathrm{L}$ de água nuclease-free. Um controle negativo, usando água como amostra, foi preparado em cada amplificação para descartar contaminações da PCR. As condições de amplificação foram: de $95^{\circ} \mathrm{C}$ por 2 min para desnaturação inicial; seguido, de 12 ciclos de $94^{\circ} \mathrm{C}$ por 30 s, anelamento dos primers a $68^{\circ} \mathrm{C}, 66^{\circ} \mathrm{C}, 64^{\circ} \mathrm{C}$ e $62^{\circ} \mathrm{C}$ (cada temperatura por três ciclos) e extensão a $72^{\circ} \mathrm{C}$ durante $60 \mathrm{~s}$; depois foram realizados 25 ciclos de $94^{\circ} \mathrm{C}$ por $30 \mathrm{~s}, 60^{\circ} \mathrm{C}$ por $30 \mathrm{~s}$ e $72^{\circ} \mathrm{C}$ por 60 s; por fim $5 \mathrm{minu}-$ tos a $72^{\circ} \mathrm{C}$. Os produtos da PCR foram analisados em eletroforese em gel de agarose a $1,5 \%$ e os produtos com tamanho específico foram purificados usando o NucleoSpin ${ }^{\circledR}$ Gel and PCR Clean-up (Macherey-Nagel, Düren, Germany). Em seguida, $10 \mu \mathrm{L}$ de produtos de PCR purificado com $5 \mu \mathrm{L}$ do primer DNM-1 Reverse foram submetidos ao sequenciamento direto usando o BigDye ${ }^{\circledR}$ Terminator Cycle Sequencing Kit (Life Technologies ${ }^{\mathrm{TM}}$, CA, USA) e o sequenciador ABI 3500 Genetic Analyzer (Life Technologies ${ }^{\mathrm{TM}}$, CA, USA). As sequências obtidas foram alinhadas e comparadas à sequência de RNAm Canis lupus familiaris dynamin 1 (EU682271) utilizando o BLAST (Basic Local Alignment Search Tool, http:// blast.ncbi.nlm.nih.gov/Blast.cgi). A análise dos resultados foi realizada com base descritiva frente ao percentual de animais com o SNP em homozigose ou heterozigose em relação à população total de 321 cães. 0 registro clínico dos animais que apresentaram o
SNP em homozigose foi avaliado. Todos os procedimentos foram previamente aprovados pelo Comitê de Ética em Experimentação Animal da FMVZ, Unesp, Botucatu (Processo n² 24/2013) e autorizados pelos proprietários dos animais.

\section{RESULTADOS E DISCUSSÃO}

As amostras obtidas por swab bucal resultaram em concentrações cerca de 4 vezes menores que as obtidas a partir de sangue total (média, 4,9 vs. 20,7 ng/ $\mu \mathrm{L}$ ), porém forneceram material suficiente para que a PCR fosse realizada adequadamente. Dessa forma, ressalta-se que essa técnica de colheita mais simples pode ser usada como um meio para obtenção do DNA para análises de mutações.

De acordo com IBGE, o Estado de São Paulo divide-se em 63 microrregiões geográficas, sendo que os animais incluídos neste estudo eram provenientes de 37 cidades que pertenciam a 16 microrregiões do Estado de São Paulo (Fig.1). Contudo, devido à proximidade com o HV-FMVZ (Unesp Botucatu) o maior número de animais era proveniente da microrregião de Botucatu (47\%, 152/321) (Quadro 1).

A ocorrência de animais E/E e E/N foi de 3,4\% (11/321) e 24,6\% (79/321), respectivamente. 0 restante dos animais $(72,0 \%, 231 / 321)$ não possuía este SNP (wild type). Utilizando a PCR seguida de restrição enzimática, Patterson et al. (2008) genotiparam cerca de 400 cães da raça Labrador Retriever de 22 estados americanos e três estados canadenses e observaram que a frequência de animais $\mathrm{E} / \mathrm{E}$ e E/N foi de $3 \%$ e $37 \%$, respectivamente. Usando esta mesma técnica, Minor et al. 2011, genotiparam 860 Labradores Retrievers dos EUA e Canadá e observaram a ocorrência de

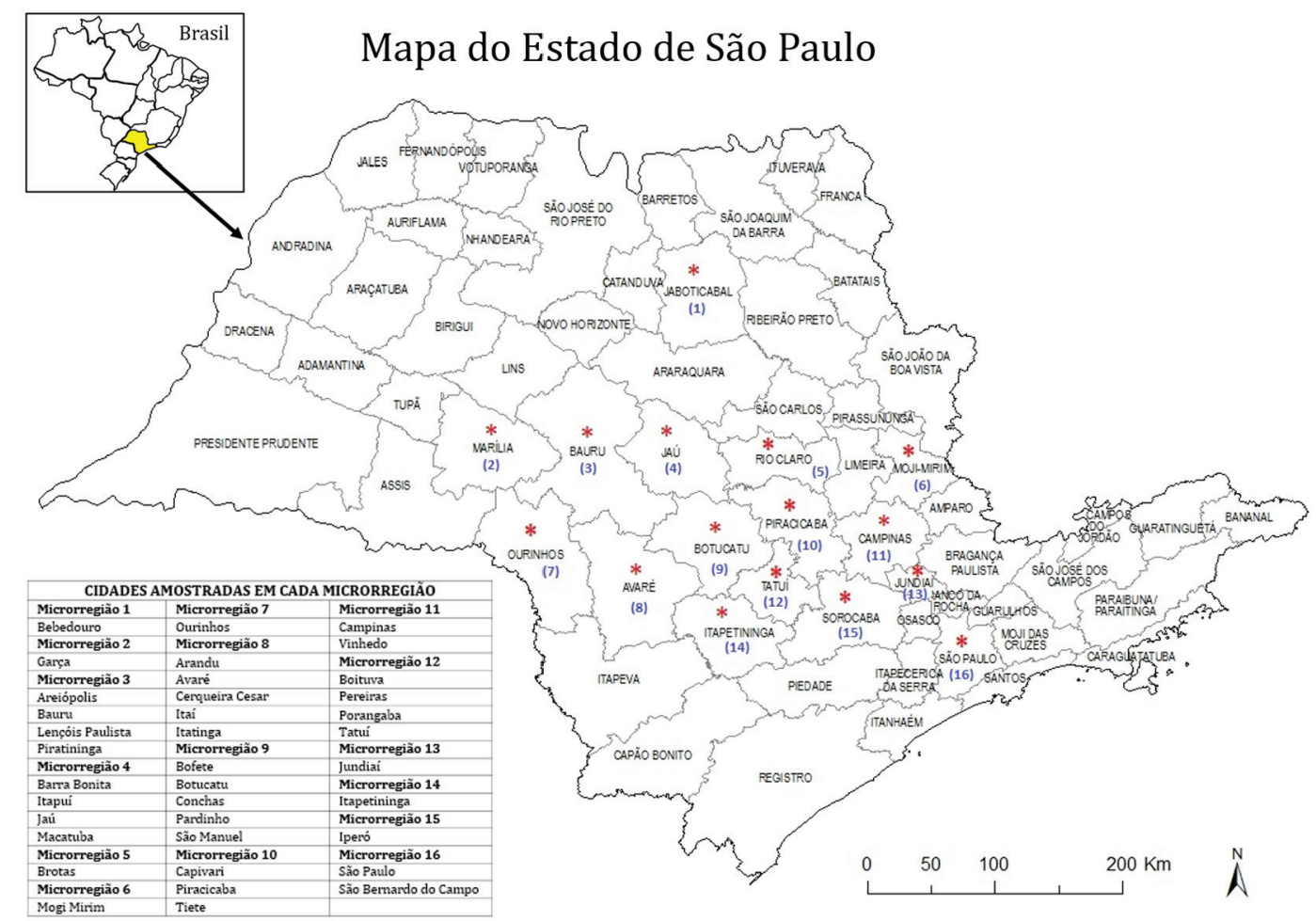

Fig.1. Mapa temático com as 16 Microrregiões geográficas $(*)$ e das 37 cidades (quadro em destaque) que tiveram amostras colhidas para verificar a ocorrência do SNP c.767G>T no gene DNM1 em cães da raça Labrador Retriever. Figura Adaptada de http://www. mapasparacolorir.com.br/mapa/estado/sp/estado-sao-paulo-microrregioes.png. 

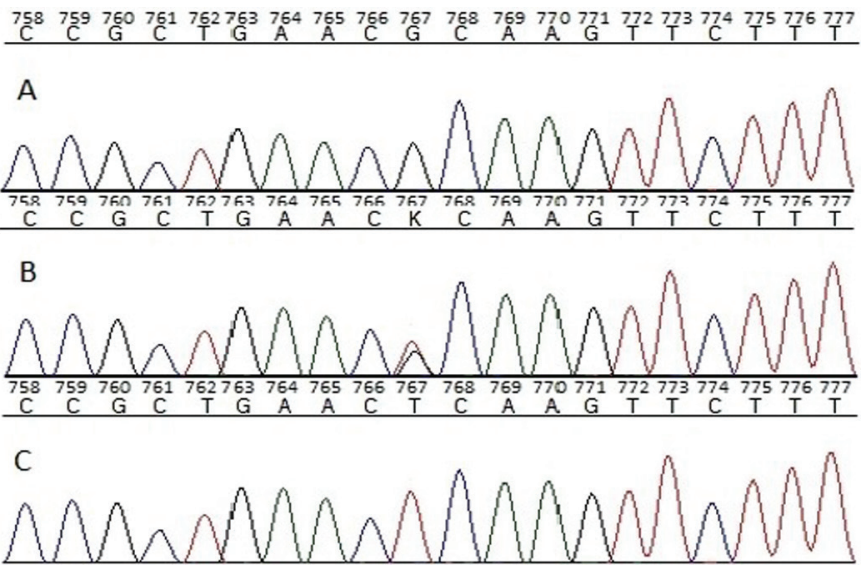

Fig.2. Eletroferograma parcial do exon 6 do gene DNM1 obtido após o alinhamento das sequências de animais wild type $(\mathrm{A})$, heterozigoto (B) e homozigoto (C) para o SNP c.767G>T. Observa-se o nucleotídeo $767 \mathrm{G}$ na sequência normal wild type, o pico duplo (K: G/T) na sequência heterozigota e o SNP (G>T) na sequência homozigota.

\section{Quadro 1. Número de animais genotipados, homozigotos e heterozigotos para o SNP c.767G > T no gene DNM1 em cães da raça Labrador Retriever distribuídos nas microrregiões geográficas do Estado de São Paulo}

\begin{tabular}{lccc}
\hline $\begin{array}{l}\text { Microrregiões } \\
\text { do Estado de } \\
\text { São Paulo }\left({ }^{*}\right)\end{array}$ & $\begin{array}{c}\text { № de Animais } \\
\text { Genotipados }\end{array}$ & $\begin{array}{c}\text { № de Animais } \\
\text { Homozigotos** }\end{array}$ & $\begin{array}{c}\text { № de Animais } \\
\text { Heterozigotos** }\end{array}$ \\
\hline Avaré (5) & 19 & 1 & 4 \\
Bauru (4) & 14 & - & 6 \\
Botucatu (5) & 152 & 2 & 42 \\
Campinas (2) & 5 & 1 & - \\
Itapetininga (1) & 1 & - & - \\
Jaboticabal(1) & 1 & - & 1 \\
Jaú (4) & 19 & 1 & 2 \\
Jundiaí (1) & 15 & - & 8 \\
Marília (1) & 2 & - & - \\
Mogi Mirim (1) & 1 & - & - \\
Ourinho (1) & 2 & - & - \\
Piracicaba & 6 & - & - \\
Rio Claro (1) & 2 & - & - \\
São Paulo (2) & 72 & 6 & - \\
Sorocaba (1) & 1 & - & 79 \\
Tatuí (4) & 9 & - & $24,6 \%)$ \\
Total & 321 & $11(3,4 \%)$ &
\end{tabular}

* Número de cidades amostradas em cada microrregião, ** Animais homozigotos ou heterozigotos para o SNP responsável pelo colapso induzido pelo exercício.

animais E/E e E/N em 6,3\% (54/860) e 34,5\% (297/860), respectivamente. Enquanto que, Takanosu et al. (2012) utilizando a PCR alelo-específica, observaram que 4,5\% (6/133) e 37,6\% (50/113) dos Labradores Retrievers estudados no Japão eram E/E e E/N, respectivamente. No presente estudo, optou-se em utilizar o sequenciamento direto de produtos de PCR (Fig.2), uma técnica padrão para identificação de mutações pontuais, como pode-se observar, a ocorrência $\mathrm{E} / \mathrm{E}$ do presente estudo foi semelhante àquela observada por outros autores (Patterson et al., 2008, Minor et al. 2011, Takanosu et al., 2012), entretanto, a porcentagem de heterozigotos no presente estudo foi menor.

Os animais E/E pertenciam a cinco microrregiões do
Estado de São Paulo (Quadro 1) e destes apenas um foi encaminhado ao HV com queixa de episódios de colapsos induzidos após o exercício, sendo este caso recentemente relatado por Basso et al. (2014). Assim como foi observado no presente estudo; onde entre os 11 animais E/E (3 machos e 8 fêmeas) quatro apresentavam pelagem amarela, três a pelagem chocolate e três a pelagem preta; a enfermidade acomete cães independentemente do sexo ou da pelagem (Taylor 2008). Em um estudo retrospectivo com 109 Labradores Retrievers com diferentes causas de colapso, todos testados geneticamente para EIC, foi evidenciado que existem algumas diferenças clínicas entre os animais com EIC (E/E) e os animais (E/N ou N/N) com outras causas de colapso (Furrow et al. 2013). Assim como descrito no animal E/E do presente estudo, que apresentou o primeiro episódio de colapso aos 12 meses de idade, os cães com EIC, avaliados por Furrow et al. (2013) também eram jovens no momento do primeiro episódio (idade média de 12 meses), o colapso normalmente se originava nos membros posteriores e se caracterizava por baixo tônus muscular e rápida recuperação. Já os cães com outras causas de colapso manifestavam os sinais com idade mais avançada (idade média de 23 meses) e tinham outros sinais além dos descritos acima, como acometimento simultâneo dos quatro membros e perda de consciência (Furrow et al. 2013). Dezessete meses é a média de idade para apresentarem os primeiros sinais clínicos nos animais que possuem a síndrome (Minor et al. 2011). 0 único animal que apresentava sinais de EIC, no presente estudo, tinha dois anos de idade, sendo o primeiro colapso descrito quando este tinha um ano de vida (Basso et al. 2014). Ao analisar os registros clínicos dos outros dez animais $\mathrm{E} / \mathrm{E}$, observou-se idade média $4,6( \pm 3,0)$ anos ao atendimento clínico e não foi evidenciado nenhum histórico ou sinal clínico compatível com EIC. Minor et al. (2011) constataram que 95,9\% dos Labradores E/E apresentam pelo menos um episódio de colapso até os quatro anos de vida, estes autores, avaliam ainda que labradores E/E jovens ( $<4$ anos) sem histórico de episódio de colapso ainda poderão expressar o fenótipo de EIC. No presente estudo seis dos dez animais E/E tinham menos que quatro anos de idade, idade média de 2,0 $( \pm 0,9)$ anos, ou seja, ainda poderiam apresentar episódios de colapso. Em estudo realizado no Japão, nenhum dos seis labradores E/E apresentavam sinais compatíveis com EIC (Takanosu et al. 2012), segundo estes autores estes animais provavelmente não tiveram ainda episódios de colapsos por que não foram submetidos a exercícios intensos. Minor et al. (2011) também apontam que labradores $\mathrm{E} / \mathrm{E}$ que não colapsaram ainda podem não terem sido submetidos a condições de exercícios intensos, estresse ou de ansiedade, contudo, estes autores também hipotetizam que labradores E/E podem ter genes modificados que aumentam ou diminuem a suscetibilidade ao colapso.

\section{CONCLUSÕES}

0 percentual de animais homozigotos e heterozigotos para EIC reforçam a necessidade de inserir a EIC dentre os diagnósticos diferenciais de enfermidades neuromusculares em cães da raça Labrador Retriever, sendo este o pri- 
meiro trabalho avaliando este polimorfismo em uma população de cães no Brasil.

A disponibilização do teste aos proprietários para confirmação da EIC e direcionamento dos acasalamentos será uma ferramenta útil para diminuir a ocorrência da doença.

Agradecimentos.- Os autores agradecem o apoio fornecido pela Fundação de Amparo à Pesquisa do Estado de São Paulo, processo 2013/03076-8.

\section{REFERÊNCIAS}

Basso R.M., Oliveira-Filho J.P., Palumbo M.I.P., Zakia L.S., Araújo Jr J.P. \& Secorun A.B. 2014. Colapso induzido pelo exercício em um Labrador Retriever. Cienc. Rural 44(9):1629-1631.

Cosford K.L. \& Taylor S.M. 2010. Exercise intolerance in retrievers. Vet. Med. 105:64-75.

Ferguson S.M., Brasnjo G., Hayashi M., Wölfel M., Collesi C., Giovedi S., Raimondi A., Gong L.W., Ariel P., Paradise S., O'toole E., Flavell R., Cremona O., Miesenböck G., Ryan T.A. \& De Camilli P. 2007. A selective activity-dependent requirement for dynamin 1 in synaptic vesicle endocytosis. Science 316:570-574.

Furrow E., Minor K.M., Taylor S.M., Mickelson J.R. \& Patterson E.E. 2013. Relationship between dynamin 1 mutation status and characteristics of recurrent episodes of exercise-induced collapse in Labrador Retrievers. J. Am. Vet. Med. Assoc. 242(6):786-791.

Matwichuk C.L., Taylor S.M., Shmon C.L., Kass P.H. \& Shelton G.D. 1999. Changes in rectal temperature and hematologic, biochemical, blood gas, and acid-base values in healthy Labrador retrievers before and after strenuous exercise. Am. J. Vet. Res. 60(1):88-92.

Minor K.M., Patterson E.E., Keating M.K., Gross S.D., Ekenstedt K.I., Taylor S.M. \& Mickelson J.R. 2011. Presence and impact of the exercise-induced collapse associated DNM1 mutation in Labrador retrievers and other breeds. Vet. J. 189:214-219.

Patterson E., Minor K.M., Tchernatynskaia A., Taylor S.M., Shelton G.D., Ekensted K. \& Mickelson J.R. 2008. A canine DNM1 mutation is highly associated with the syndrome of exercise-induced collapse. Nature Genetics 40(10):1235-1239.

Saheki Y. \& De Camilli P. 2012. Synaptic vesicle endocytosis. Cold Spring Harbor Perspectives in Biology 4:a005645

Steiss J., Ahmad H.A., Cooper P. \& Ledford C. 2004. Physiologic responses in healthy Labrador Retrievers during field trial training and competition. J. Vet. Intern. Med. 18(2):147-151

Takanosu M., Mori H., Suzuki H. \& Suzuki K. 2012. Genotyping of exercise-induced collapse in Labrador retrievers using an allele-specific PCR. Vet. J. 193(1):293-295.

Taylor S.M., Shmon C.L., Shelton G.D., Patterson E.N., Minor K. \& Mickelson J.R. 2008. Exercise-induced collapse of Labrador retrievers: Survey results and preliminary investigation of heritability. J. Am. Anim. Hospital Assoc. 44:295-301.

Taylor S.M., Shmon C.L., Adams V.J., Mickelson J.R., Patterson E.N. \& Shelton G.D. 2009. Evaluations of Labrador retrievers with exercise-induced collapse, including response to a standardized strenuous exercise protocol. J. Am. Anim. Hospital Assoc. 45:3-13. 